\title{
Silicone-Containing Biodegradable Smart Elastomeric Thermoplastic Hyperbranched Polyurethane
}

\author{
Tuhin Ghosh and Niranjan Karak*(0)
}

Advanced Polymer and Nanomaterial Laboratory, Center for Polymer Science and Technology, Department of Chemical Sciences, Tezpur University, Tezpur 784028, India

\section{Supporting Information}

ABSTRACT: Silicone-containing biobased hyperbranched polyurethane thermoplastic elastomers at different compositions were reported for the first time. The structures of the polymers were evaluated from Fourier transform infrared spectroscopy, NMR, X-ray diffraction, and energy-dispersive Xray spectroscopy analyses. The synthesized elastomers possess high molecular weight $\left(1.11-1.38 \times 10^{5} \mathrm{~g} \cdot \mathrm{mol}^{-1}\right)$ and low glass transition temperature (from -40.0 to $-27.3{ }^{\circ} \mathrm{C}$ ). These polymers exhibited multistimuli responsive excellent repeatable intrinsic self-healing (100\% efficiency), shape recovery (100\%), and efficient self-cleaning (contact angle $102^{\circ}-107^{\circ}$ ) abilities along with exceptional elongation at break (2834-3145\%), high toughness $\left(123.3-167.8 \mathrm{MJ} \cdot \mathrm{m}^{-3}\right)$, good impact resistance

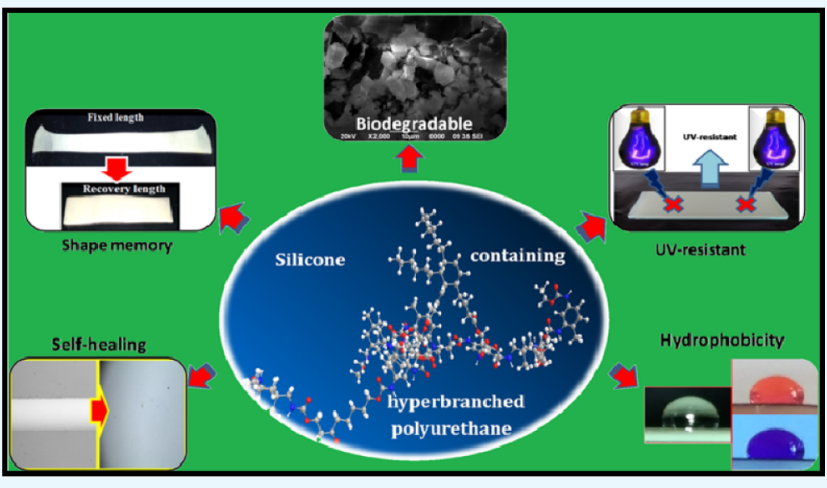
$\left(18.3-20.3 \mathrm{~kJ} \cdot \mathrm{m}^{-1}\right)$, and adequate tensile strength $(5.9-6.9$ $\mathrm{MPa})$. Furthermore, high thermal stability $\left(253-263^{\circ} \mathrm{C}\right)$ as well as excellent UV and chemical resistance was also found for the polymers. Most interestingly, controlled bacterial biodegradation under exposure of Pseudomonas aeruginosa bacterial strains demonstrated them as sustainable materials. Therefore, such biobased novel thermoplastic polyurethane elastomers with selfhealing, self-cleaning, and shape memory effects possess great potential for their advanced multifaceted applications.

\section{INTRODUCTION}

Smart high-performing polymeric materials with shape memory, self-healing, and self-cleaning effects have attracted researchers because of their widespread applications including coating, packaging, biomedical, automobile, aerospace, printing and so forth. Shape memory polymers (SMP) are considered as stimuli-responsive smart polymers which can recover their primary shape from a temporary deformed shape as required. ${ }^{1,2}$ In general, such smart polymer contains some flexible soft segment and rigid hard segment in an appropriate composition. Again, designing of self-healing polymers (SHP) maintained a great interest among researchers as such polymers healed themselves upon damage. ${ }^{3}$ On the other hand, the self-cleaning polymers retain their surfaces free from accumulation of contaminants. ${ }^{4}$ Literature advocates a few polymeric materials which can exhibit the abovementioned smart properties. Sottos et al. synthesized poly(dimethylsiloxane) (PDMS) based self-healing elastomer by incorporating resinous microencapsule with cross-linker in the matrix. ${ }^{5}$ However, such elastomers can heal only one time at a particular zone because of the exhaustion of the healing agent from the incorporated microcapsules. To overcome this limitation, designing of intrinsic SHP has been attempted by various approaches such as molecular diffusion, reversible breaking, and reforming of dynamic covalent or noncovalent bonds induced by heat energy, incorporation of nano materials, and so forth. ${ }^{6,7}$ Zhao et al. synthesized poly(siloxaneurethane)-based self-healing elastomer with shape memory attributes but the time and temperature required for the healing were too high. ${ }^{2}$ Urban and Ghosh reported an oxetanesubstituted chitosan-containing self-healing polyurethane (PU) network, although the synthetic procedure is critical. ${ }^{8}$ Furthermore, over the last few decades, self-healing has become much more attractive to the researchers because of amalgamation of supramolecular chemistry in the healing process. For example, Roy et al. used a dynamic self-healing approach through multihydrogen bonding. ${ }^{9}$ Several reports have also been found where healing was achieved through the metal-ligand interactions. ${ }^{10,11}$ However, the abovementioned polymeric material showed low mechanical property. Thus, all of the polymers reported above have some demerits and hence urge upon new development.

Again, a superhydrophobic or photocatalytic surface can provide self-cleaning ability to the polymeric materials. ${ }^{12}$ However, water-repellent capacity of the artificial superhydrophobic surface gradually decreases with the accumulation of contaminants and the natural weathering process, though it is not observed in such naturally occurring surfaces including

Received: April 16, 2018

Accepted: June 12, 2018

Published: June 25, 2018 
Scheme 1. Plausible Synthesis Route of HSPU1

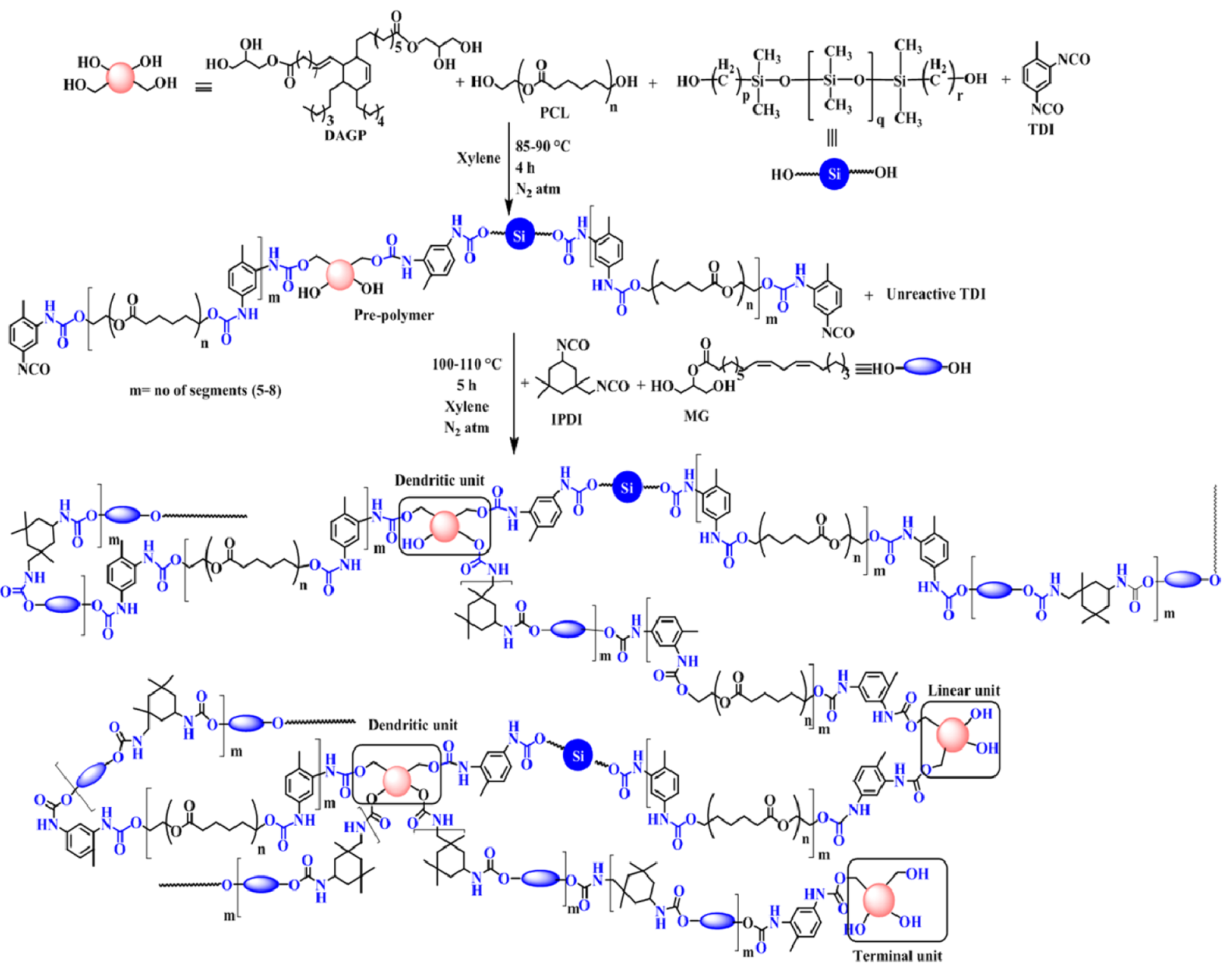

lotus leaves because they can easily reform or regenerate the same. ${ }^{13}$ On the other hand, degradation of contaminants by the photocatalytic effect requires an external photoresponsive material. Furthermore, the approach may also degrade the parent polymer. Therefore, a hydrophobic surface with high weathering resistance nature may be the right choice to achieve self-cleaning property. In this milieu, Ramakrishna et al. synthesized PU-containing octadecyl chain-grafted silica nanoparticles by employing silanol-isocyanate reaction, which exhibited self-healing ability along with self-cleaning property. ${ }^{14}$ Bayer et al. synthesized a superhydrophobic PU by incorporation of nanoclay. ${ }^{15}$ Thus, the design of a polymer with all these smart behaviors is highly challenging, if no external agent is used. Molecular engineering with the right composition of the appropriate components of an elastomeric PU may be an apt choice, in this context. This is due to the inherent advantages of PUs among other polymers. ${ }^{1}$ These include easy production with tunable properties, inherent structural inhomogeneity within the chain, and wide range of applications.

Furthermore, renewable resource-based elastomeric PU can offer desired biodegradability along with sustainability. In addition, incorporation of branching in the structure of such PU not only improves its processing characteristics, but it may also lead to some unique and useful properties. Thus, studies on biobased hyperbranched PU thermoplastic elastomers with the smart behaviors mentioned above will be very interesting and may lead to different advanced applications. The authors, therefore, attempted to achieve combined smart attributes such as shape memory, self-cleaning, and self-healing in the reported biobased hyperbranched PU thermoplastic elastomer. The mechanical, thermal, UV-resistant, and biodegradability properties of the elastomers were also evaluated. The authors also tried to establish the structure-property relationship of such an elastomer.

\section{RESULTS AND DISCUSSION}

Synthesis and Characterization of PUs. Hyperbranched silicone-containing PU 1 (HSPU1) was synthesized by a onepot prepolymerization technique, as shown in Scheme 1. In the first step, to synthesize an isocyanate-terminated prepolymer, an excess amount of aromatic isocyanate, 2,4/2,6-toluene diisocyanate (TDI) $\left(\mathrm{B}_{2}\right)$, was reacted with poly $(\varepsilon$ caprolactone)diol (PCL) $\left(\mathrm{A}_{2}\right)$, PDMS $\left(\mathrm{A}_{2}^{\prime}\right)$, and a biobased macroglycol, dimer acid-glycerol-modified polyol (DAGP) $\left(\mathrm{A}_{2} \mathrm{~A}_{2}^{\prime}\right)$. DAGP was used as the branch generating unit. In the second step, the chain extension was completed by reacting this prepolymer with monoglyceride $(\mathrm{MG})$ of sunflower oil 
$\left(\mathrm{A}_{2}^{\prime \prime}\right)$ and aliphatic isocyanate and isophorone diisocyanate (IPDI) $\left(\mathrm{B}_{2}^{\prime}\right)$. The overall $\mathrm{NCO} / \mathrm{OH}$ ratio was maintained as unity, as given in Table 1. IPDI contains primary and

Table 1. Composition of the Reactants and Physical Parameters of the Synthesized PUs

\begin{tabular}{lcccc} 
reagents $(\mathrm{mM})$ /parameter & HSPU1 & HSPU2 & HSPU3 & LSPU \\
PCL & 2.1 & 2 & 1.9 & 2 \\
PDMS & 0.1 & 0.2 & 0.3 & 0.2 \\
DAGP & 0.2 & 0.2 & 0.2 & \\
BD & & & & 0.4 \\
MG & 4.6 & 4.6 & 4.6 & 4.6 \\
TDI & 3.2 & 3.2 & 3.2 & 3.2 \\
IPDI & 4 & 4 & 4 & 4 \\
NCO/OH ratio & 1 & 1 & 1 & 1 \\
soft segment (wt \%) & 61.5 & 63.2 & 64.7 & 62.2 \\
hard segment (wt \%) & 38.5 & 36.8 & 35.3 & 37.8 \\
branching unit (wt \%) & 1.8 & 1.8 & 1.7 & \\
biobased content (wt \%) & 22.3 & 21.3 & 20.4 & 19.7 \\
wt \% of PDMS & 7 & 13.4 & 19.2 & 13.6 \\
\hline
\end{tabular}

secondary isocyanate groups which help to continue the reaction in a step by step manner according to their reactivities. ${ }^{16}$ The good quality $\mathrm{PU}$ without any gel product was obtained through this approach by controlling the reaction temperature, rate of addition of the reactants, reaction time, and speed of agitation. Further, to achieve the optimum performance, the amount of hard and soft segments was kept around $35.3-38.5 \%$ and $61.4-64.6 \%$, respectively, as found in most of the earlier reported similar segmented PUs. ${ }^{1,17}$ The presently synthesized PUs may be biodegradable, as they contain easily hydrolysable ester and urethane linkages in the structure as well as can be used as an alternative to petroleumbased PUs, as they contain 19.7-22.8\% biobased components.

Chemical Structure Analysis. The Fourier transform infrared (FT-IR) spectra of synthesized HSPUs along with linear silicone-containing PU (LSPU) are displayed in Figure 1. The absence of the band at about $2270 \mathrm{~cm}^{-1}$ supports the absence of the free isocyanate group in the chains of PUs. ${ }^{18,19}$ Thus, the reaction may be completed. Further, the presence of the band at around $3436 \mathrm{~cm}^{-1}$ is attributed to the stretching frequency of the $\mathrm{N}-\mathrm{H}$ bond. A shoulder band at $1742 \mathrm{~cm}^{-1}$ is assigned to the carbonyl stretching frequency of the ester $(\mathrm{O}-$ $\mathrm{C}=\mathrm{O}$ ) linkage, and a band at $1638 \mathrm{~cm}^{-1}$ is assigned to the carbonyl stretching frequency of the amide $(-\mathrm{NH}-\mathrm{C}=\mathrm{O})$ linkage. Again, the band at $1020 \mathrm{~cm}^{-1}$ represents the $\mathrm{O}-\mathrm{C}=\mathrm{O}$ stretching frequency. The information given above supports the presence of the urethane linkage $-\mathrm{NH}-(\mathrm{C}=\mathrm{O})-\mathrm{O}-$ in the structure of synthesized PUs. On the other hand, the absorption bands at 2925 and $2852 \mathrm{~cm}^{-1}$ represent the $\mathrm{sp}^{3}$ hybridized $\mathrm{C}-\mathrm{H}$ bond of asymmetric and symmetric stretching frequencies. Again, the band at $1267 \mathrm{~cm}^{-1}$ corresponds to the bending vibration frequency of the $-\mathrm{CH}_{3}$ moiety of PDMS. The absorption bands at 1100 and $1020 \mathrm{~cm}^{-1}$ are assigned to the asymmetric and symmetric stretching vibration frequencies of the $\mathrm{Si}-\mathrm{O}-\mathrm{Si}$ bond, while the band at $794-800 \mathrm{~cm}^{-1}$ is accredited to the $\mathrm{Si}-\mathrm{C}$ stretching and $-\mathrm{CH}_{3}$ rocking. ${ }^{18}$

The energy-dispersive $\mathrm{X}$-ray spectroscopic analyses confirmed the presence of $\mathrm{C}, \mathrm{O}$, and $\mathrm{Si}$ elements in the structure of HSPU3 (Figure 1b) with weight and atomic percentages of $59.09,34.56$, and 6.34 and 67.34, 29.57, and 3.09, respectively.

Furthermore, the structure of HSPU1 was supported by the NMR spectral study. In the ${ }^{1} \mathrm{H}$ NMR spectrum (Figure 2a), the peaks at 0.85 (a), 0.90 (b), 0.95 (c), and 2.56 (d) ppm correspond to terminal methyl protons of PDMS, MG, and DAGP and IPDI and TDI moieties. The peaks at 1.23-1.35

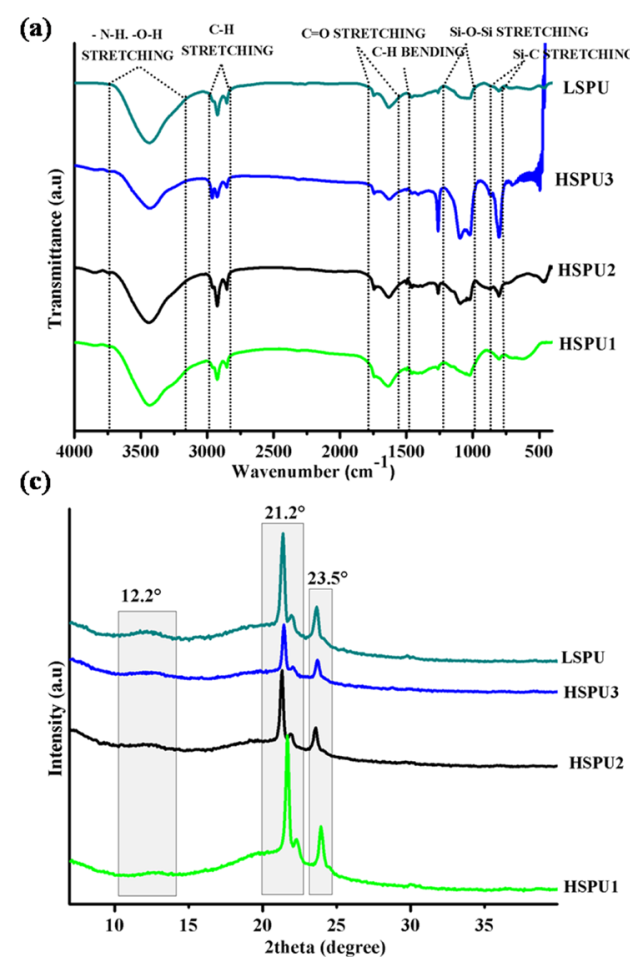

(b)
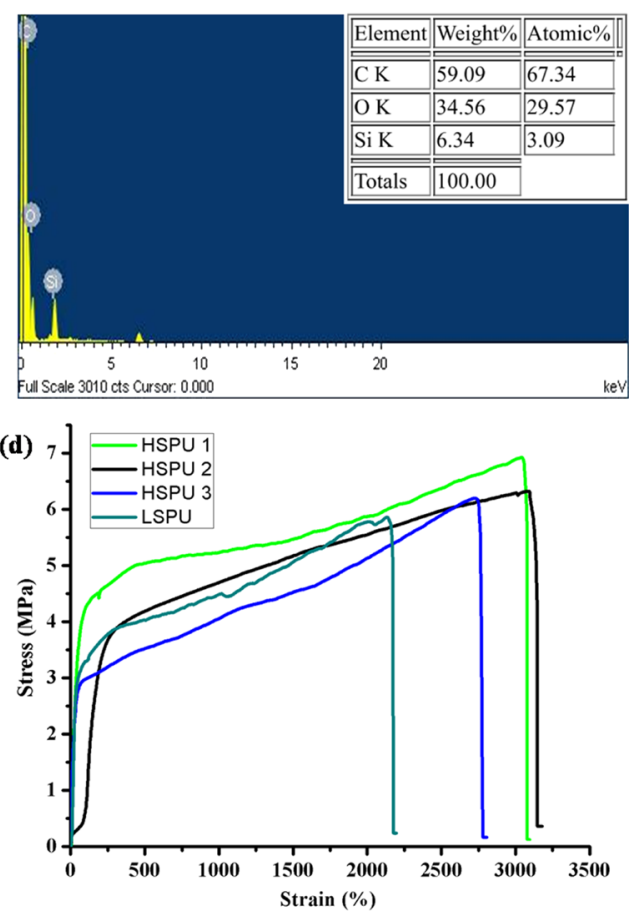

Figure 1. (a) FT-IR spectra of PUs, (b) energy-dispersive X-ray spectroscopy spectrum of HSPU3, (c) X-ray diffractograms, and (d) stress-strain profiles of PUs. 
(a)
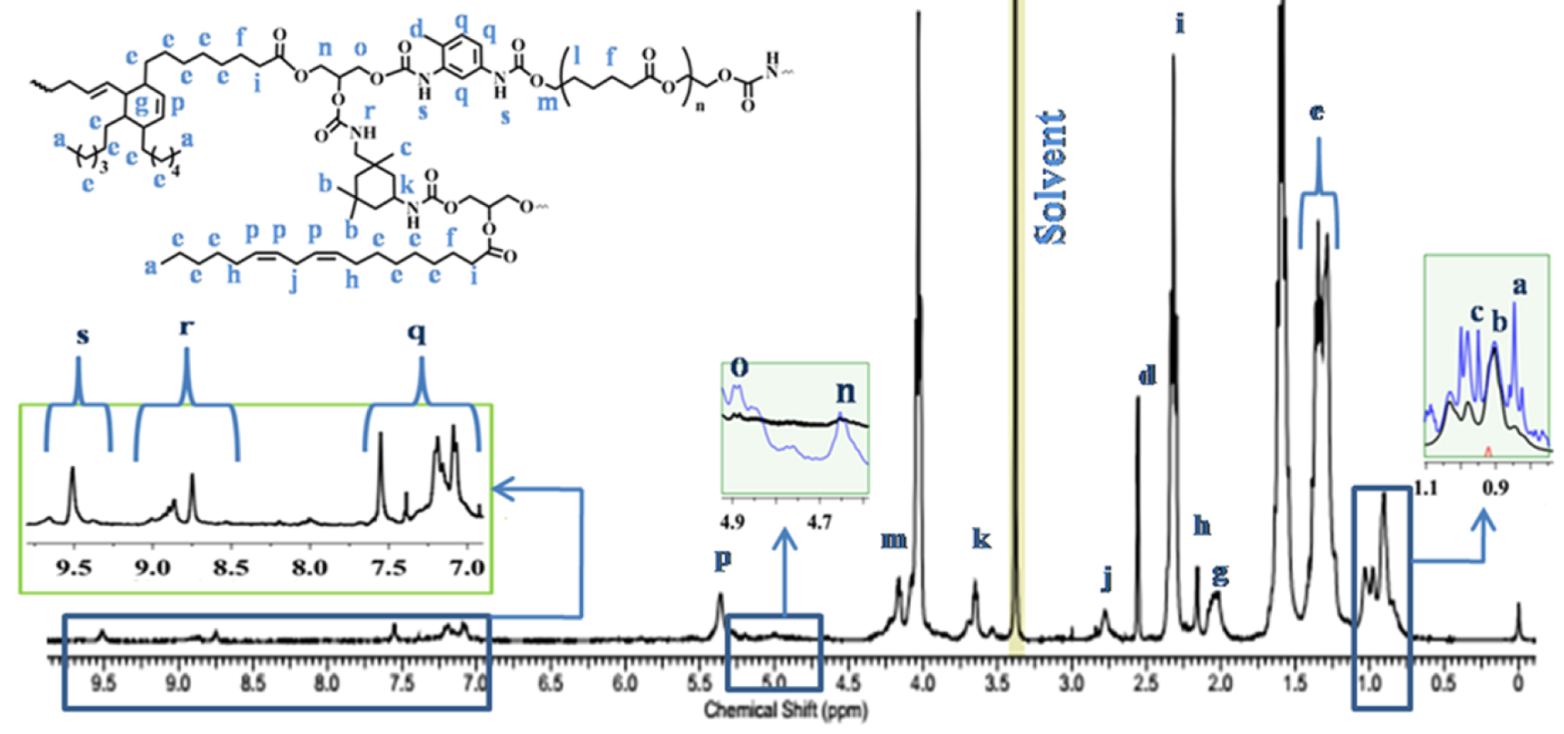

(b)

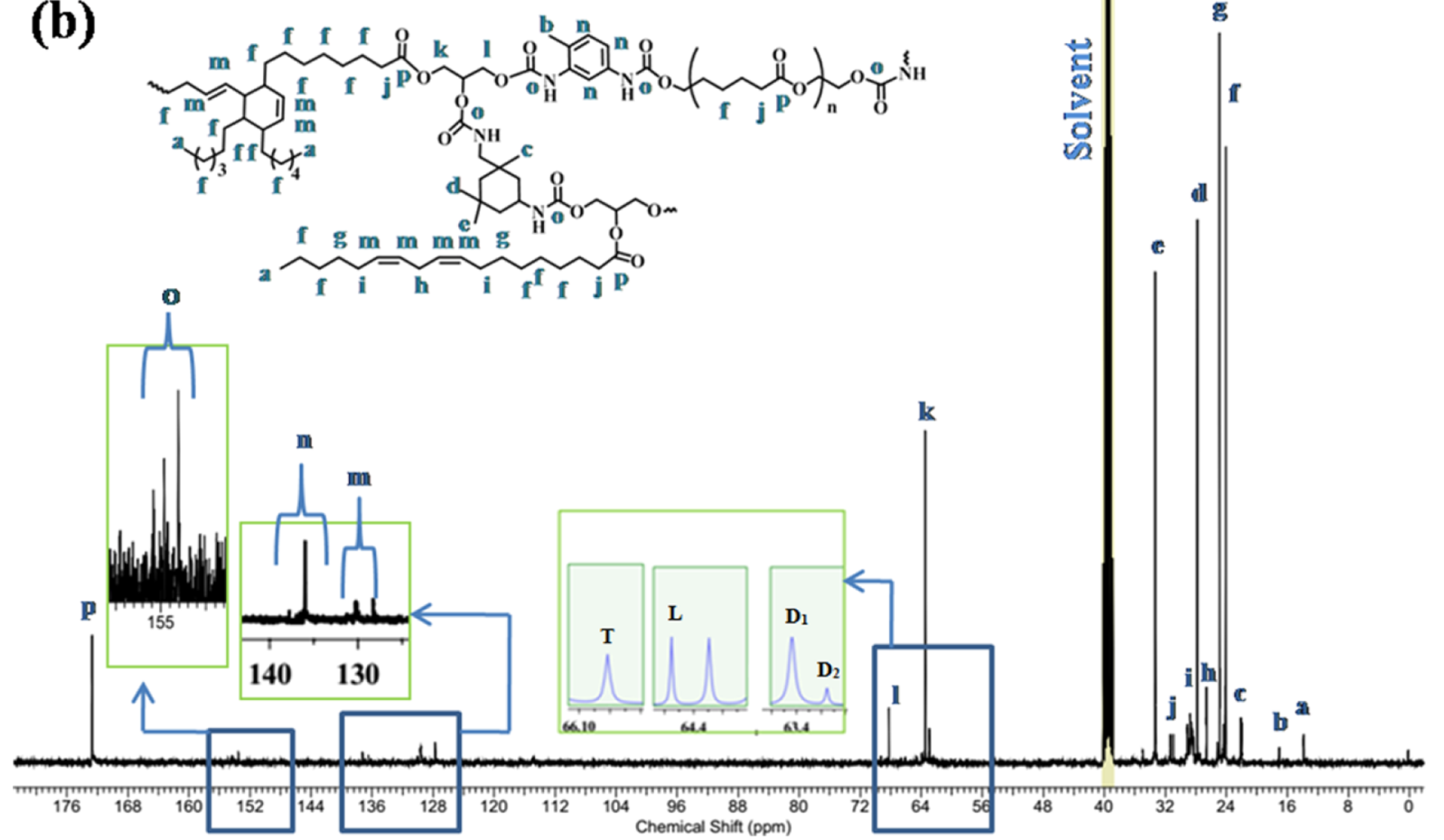

Figure 2. (a) ${ }^{1} \mathrm{H}$ NMR and (b) ${ }^{13} \mathrm{C}$ NMR spectra of HSPU1.

(e) ppm represented the methylene protons of PDMS, DAGP, PCL, and MG. Again, the peaks that appeared at 2.32 (i) and 1.58 (f) ppm are due to methylene protons $(\alpha$ and $\beta)$ of PCL and DAGP, with respect to the ester group. The peaks at 2.05 $(\mathrm{g}), 2.16(\mathrm{~h})$, and $2.77(\mathrm{j}) \mathrm{ppm}$ are attributed to the protons adjacent to the double bond of the DAGP moiety, whereas the protons attached to $\alpha$ carbon of the double bond and methylene protons between the double bond of MG. The peaks at $3.65(\mathrm{k}), 4.17(\mathrm{~m})$, and $4.03(\mathrm{l}) \mathrm{ppm}$ are due to the protons of IPDI, adjacent to the amide bond and $\alpha$ and $\beta$ carbons to oxygen of the ester linkage. Methylene protons of the glycerol moiety were observed at 4.65 (n) and 4.89 (o) ppm. Aromatic protons of TDI and aliphatic protons of the double bond, associated with MG and DAGP, appear at 7.07.5 (q) and $5.34(\mathrm{p}) \mathrm{ppm}$. The $-\mathrm{NH}$ protons of urethane bonds of IPDI and TDI are assigned at $8.75-8.87(\mathrm{r})$ and 9.51 ppm (s). In the ${ }^{13} \mathrm{C}$ NMR spectrum (Figure $2 \mathrm{~b}$ ), peaks for methyl carbon of PDMS, MG, DAGP, and TDI moieties appeared at 14.41 (a) and 17.83 (b) ppm. The peaks that appeared at 22.51 (c), 28.3 (d), and 33.76 (e) ppm are due to three different methyl carbons of IPDI. The peaks found in the region 24.60 (f), 25.41 (g) $27.23(\mathrm{~h}), 29.26(\mathrm{i})$, and $31.56(\mathrm{j})$ ppm correspond to methylene carbons of DAGP, PDMS, MG, PCL, the methylene carbon between two double bonds, methylene carbon $\alpha$ to the double bond and the ester group. The peaks at $63.98(\mathrm{k})$ and $68.74(\mathrm{l}) \mathrm{ppm}$ are associated with 
Table 2. Physical and Mechanical Properties of PUs

\begin{tabular}{|c|c|c|c|c|}
\hline properties & HSPU1 & HSPU2 & HSPU3 & LSPU \\
\hline color & off white & off white & off white & off white \\
\hline specific gravity & 1.58 & 1.67 & 1.83 & 1.70 \\
\hline solution viscosity $(\mathrm{dL} / \mathrm{g})$ at $30{ }^{\circ} \mathrm{C}$ & 0.163 & 0.247 & 0.299 & 0.325 \\
\hline$M_{\mathrm{n}}\left(\mathrm{g} \mathrm{mol}^{-1}\right)$ & 97995 & 89703 & 73159 & 91675 \\
\hline$M_{\mathrm{w}}\left(\mathrm{g} \mathrm{mol}^{-1}\right)$ & 138247 & 136097 & 118715 & 138839 \\
\hline PDI & 1.41 & 1.51 & 1.62 & 1.51 \\
\hline tensile strength $(\mathrm{MPa})$ & $6.9 \pm 0.1$ & $6.3 \pm 0.2$ & $5.9 \pm 0.5$ & $5.8 \pm 0.4$ \\
\hline elongation at break (\%) & $3076 \pm 100$ & $3145 \pm 60$ & $2834 \pm 80$ & $2349 \pm 200$ \\
\hline impact resistance $\left(\mathrm{kJ} \cdot \mathrm{m}^{-1}\right)$ & $20.3 \pm 0.3$ & $18.9 \pm 0.6$ & $18.3 \pm 0.3$ & $16.6 \pm 0.2$ \\
\hline scratch hardness $(\mathrm{kg})$ & $3.6 \pm 0.3$ & $3.5 \pm 0.1$ & $3.0 \pm 0.2$ & $2.5 \pm 0.1$ \\
\hline toughness $\left(\mathrm{MJ} \cdot \mathrm{m}^{-3}\right)$ & $167.8 \pm 2.3$ & $156.5 \pm 1.8$ & $123.3 \pm 1.5$ & $99.70 \pm 2.5$ \\
\hline modulus at $200 \%$ strain $(\mathrm{MPa})$ & 22.73 & 16.32 & 15.45 & 18.18 \\
\hline
\end{tabular}

the methylene carbons of the glycerol moiety. The peaks for the double-bonded and aromatic carbons appeared in between the region 128.56-130.13 (m) and 136.1-137.9 (n) ppm. The peaks found at 154.02-155.48 (o) and 171.4-175.3 (p) ppm are attributed to the urethane carbon and ester carbon, respectively. The peaks at $63.44\left(\mathrm{D}_{1}\right), 63.17\left(\mathrm{D}_{2}\right), 64.46\left(\mathrm{~L}_{1}\right)$, and $66\left(\mathrm{~T}_{1}\right) \mathrm{ppm}$ were observed in the ${ }^{13} \mathrm{CNMR}$ spectrum of HSPU1 representing the carbon atoms of tetra-, tri-, di-, and monosubstituted DAGP moiety. ${ }^{19,20}$ The DB of HSPU1 was found to be 0.78 , as determined by using the integration of the corresponding peaks for $\mathrm{D}_{1}, \mathrm{D}_{2}, \mathrm{~L}_{1}$, and $\mathrm{T}_{1}$.

$$
\mathrm{DB}=\left(\mathrm{D}_{1}+\mathrm{D}_{2}+\mathrm{T}_{1}\right) /\left(\mathrm{D}_{1}+\mathrm{D}_{2}+\mathrm{T}_{1}+\mathrm{L}_{1}\right)
$$

Physical Structure. X-ray diffraction (XRD) patterns of HSPUs along with LSPU are shown in Figure 1c. The degree of crystallinity in all PUs varies from 17.4 to $22.4 \%$ because of different wt \% PCL and PDMS content. However, the crystalline nature of PUs remains almost the same. The XRD study revealed an amorphous halo at $12.2^{\circ}$ because of the PDMS moiety, while two peaks at $21.2^{\circ}$ (calculated $d$ spacing of $4.18 \AA$ ) and $23.5^{\circ}$ (calculated $d$ spacing of $3.78 \AA$ ) correspond to the (110) and (200) planes of the orthorhombic lattice structure of the crystalline PCL moiety. ${ }^{21}$ The intensity of the peaks decreases with the increase in the amount of PDMS. Thus, the peak in HSPU1 showed higher intensity compared to the others. HSPU3 has the maximum amount of PDMS, and thus, it has the least intensity. The peak intensities of HSPU2 and LSPU were almost similar because of the similar amount of PCL content.

Physical Properties. The measured physical properties of PUs are tabulated in Table 2. One the most important physical characteristics is solubility. HSPUs were found to be soluble in polar aprotic solvents such as tetrahydrofuran, dimethylacetamide, dimethylformamide, and dimethyl sulfoxide and halogenated solvents such as chloroform, dichloromethane, and so forth. The solubility was also observed in acetone, though PUs were insoluble in hexane, ethanol, and so forth. This good solubility is accredited to the hyperbranched structure of HSPUs and the presence of polar hydroxyl, ester, and urethane groups along with the nonpolar long flexible hydrocarbon moiety in them. The specific gravity $(1.58-1.83)$ and solution viscosity values of HSPUs were also found to be increased with the increase in the content of PDMS. However, the solution viscosity of PUs was found to be slightly low, compared to their molecular weight. Compared to LSPU, HSPUs possess lower solution viscosity which is because of unique structural geometry HSPUs. The average molecular weight was found to be in the order of $10^{5}$, which seems to be very high (Table 2). The molecular weight was found to follow a decrease in the trend with the increase of PDMS content. Furthermore, the low polydispersity index (PDI) of HSPUs (1.41-1.62) showed a well-defined property. $^{22}$

The morphology of the synthesized PUs was highly affected by the structure, chemical compositions, processing condition, viscosity, miscibility, and crystallinity of the components. ${ }^{23}$ Optical images of the synthesized PUs were taken, and these images were further processed with the help of ImageJ software to display the difference in the morphology among the PUs. From the surface $3 \mathrm{D}$ plot images, it is clearly evident that roughness of the PUs increases from HSPU1 to HSPU3. This is might be due to the incompatibility between crystalline PCL and amorphous PDMS moiety in the molecular level, resulting in the spherulitic pattern, as shown in Figure S2. ${ }^{21}$ The intensity of the spherulitic pattern increases with the increase of the amount of PDMS. Thus, HSPU3 exhibited the roughest architecture among HSPU2, HSPU1, and LSPU.

Mechanical Properties. Mechanical properties (displayed in Table 2) of the PU strips were strongly influenced by the molecular weight of PUs and their soft segment, hard to soft segment ratio, crystallinity, physical cross-linking, chain entanglement, orientation of segments, hydrogen bonding, and so forth. From the stress-strain curves (Figure 1d), it is evident that all PUs showed outstanding elongation at break as well as good tensile strength. The elastomeric behavior of PUs is due to the high molecular weight of the polymer and low glass transition temperature (as discussed later). Exceptionally high elongation at break (flexibility) of the synthesized PUs is attributed to the high molar mass $\left(10^{5}\right.$ order $)$, long flexible hydrocarbon chains of MG and DAGP in the structure of the polymer along with the presence of primary and secondary interactions. In addition, high flexibility of the $\mathrm{Si}-\mathrm{O}-\mathrm{Si}$ bond (bond angle of the $\mathrm{Si}-\mathrm{O}-\mathrm{Si}$ bond varies from $140^{\circ}$ to $160^{\circ}$ ) in the structure of the PDMS moiety also supports high elongation of molecular chains under the direction of applied force. ${ }^{24}$ Further, these elongation at break values of HSPUs were found to be much higher than the other reported PUs. ${ }^{25,26}$ The presence of aromatic and aliphatic diisocyanates (TDI and IPDI) with a chain extender (MG) as the hard segment, crystallinity, large amount of secondary interactions, and higher H-bonding in hard segments (compared to the soft segments) provide rigidity of the synthesized PUs. The strength of HSPUs decreases with the increase of the flexible PDMS content. The combination of exceptionally high 

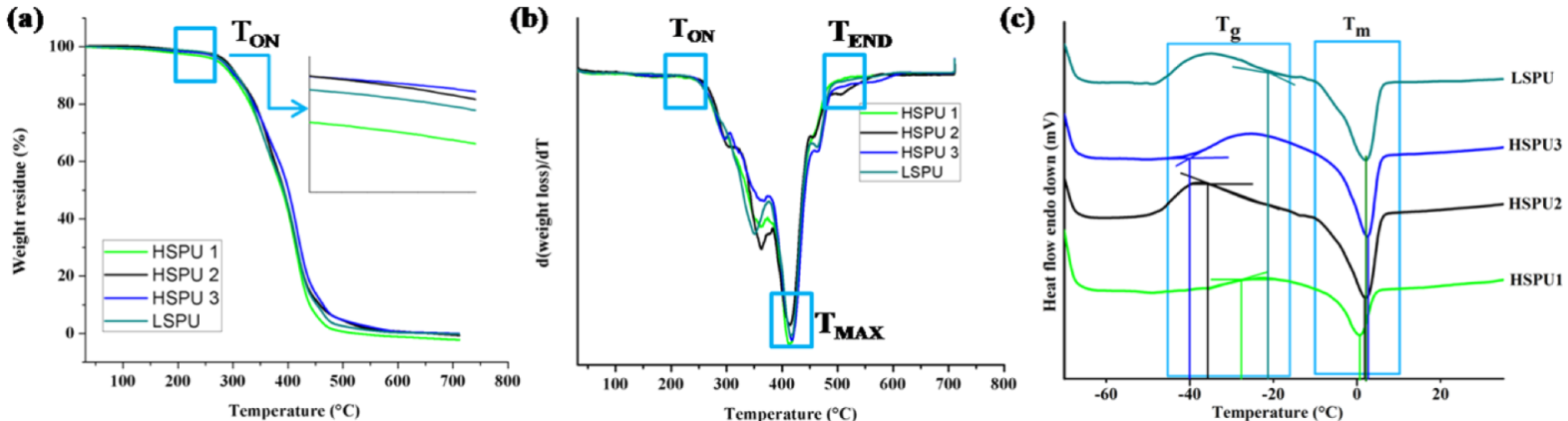

Figure 3. (a) TGA thermograms, (b) DTG curves, and (c) DSC curves with glass transition and melting temperature of PUs.

Table 3. Thermal Property, Self-Healing Time, Shape Memory, Contact Angles of PUs, and Retention (\%) of Mechanical Properties of UV-Aged PUs

\begin{tabular}{lllll} 
& \multicolumn{1}{c}{ parameter } & HSPU1 & HSPU2 & \multicolumn{1}{c}{ HSPU3 } \\
$T_{\mathrm{ON}}\left({ }^{\circ} \mathrm{C}\right)$ & 253 & 260 & 263 & 255 \\
$T_{\mathrm{MAX}}\left({ }^{\circ} \mathrm{C}\right)$ & 414 & 414 & 417 & 414 \\
$T_{\mathrm{END}}\left({ }^{\circ} \mathrm{C}\right)$ & 525 & 540 & 543 & 538 \\
$T_{\mathrm{g}}\left({ }^{\circ} \mathrm{C}\right)$ & -27.3 & -35.7 & -40.0 & -21.2 \\
$T_{\mathrm{m}}\left({ }^{\circ} \mathrm{C}\right)$ & 1 & 1.8 & 2.6 & 2.1 \\
crystallinity (\%) & 20.4 & 19.10 & 17.4 & 22.4 \\
self-healing time under MW (s) & $58 \pm 3$ & $60 \pm 2$ & $78 \pm 5$ & $62 \pm 2$ \\
shape fixity (\%) & $97.7 \pm 0.5$ & $84.7 \pm 0.8$ & $77.7 \pm 1.5$ & 100 \\
shape recovery (\%) & 100 & 100 & 100 & 100 \\
shape recovery time under MW (450 W) (s) & $41 \pm 1$ & $45 \pm 1$ & $52 \pm 3$ & $57 \pm 2$ \\
shape recovery time under sunlight (s) & $342 \pm 12$ & $356 \pm 8$ & $389 \pm 14$ & $395 \pm 5$ \\
advancing angle & $102.8^{\circ} \pm 2^{\circ}$ & $104.7^{\circ} \pm 1^{\circ}$ & $107^{\circ} \pm 1^{\circ}$ & $103.8^{\circ} \pm 1.2^{\circ}$ \\
receding angle & $100.8^{\circ} \pm 2^{\circ}$ & $103.2^{\circ} \pm 1^{\circ}$ & $105.4^{\circ} \pm 1^{\circ}$ & $101.8^{\circ} \pm 1.2^{\circ}$ \\
angle of hysteresis & $2^{\circ}$ & $1.6^{\circ}$ & $1.6^{\circ}$ & $2^{\circ}$ \\
tensile strength retention (\%) & $98.5 \pm 0.6$ & 98.6 & $100 \pm 1.3$ & $97.4 \pm 3$ \\
elongation at break retention (\%) & $82.9 \pm 3$ & $85.1 \pm 5$ & $84.5 \pm 2$ & 79.6
\end{tabular}

elongation and good tensile strength makes the synthesized PUs mechanically tough. The toughness of PU strips was calculated from the area under the stress-strain curve. HSPUs showed comparatively better mechanical property than its linear analogue, LSPU, because of the hyperbranched architecture and the presence of large numbers of secondary interactions. The impact resistance values of HSPUs and LSPUs were also found to be high (greater than the maximum limit of the used instrument), which may be because of high flexibility and strength of the former. As the maximum height of the instrument is $1 \mathrm{~m}$ and the energy per unit thickness corresponding to the maximum height until which the film is not damaged was taken as the impact resistance, the energy value also depends on the thickness of the sample. Thus, even though the falling height was the same for each reported value, the exact value of corresponding energy may vary because of the difference in thickness of the films. Similarly, scratch hardness of both HSPUs also decreases with the increase of the soft segment content. Overall, the mechanical properties of the synthesized PUs were found to be significantly higher than the reported biobased PUs. ${ }^{2}$

Thermal Properties. Generally, thermal stability of PUs depends on several factors such as chemical structure, composition, urethane linkages, molecular weight, degree of virtual cross-linking points, and intra-/intermolecular forces. Three-step degradation patterns were observed from the thermogravimetric analysis (TGA) thermograms as well as their corresponding derivative thermogravimetry (DTG) curves (Figure 3a,b) of the synthesized PUs. ${ }^{27,28}$ The onset degradation temperature $\left(T_{\mathrm{ON}}\right)$ ranging from 253 to $263{ }^{\circ} \mathrm{C}$ is due to the presence of thermolabile moieties such as the terminal methyl group of TDI and long aliphatic chains of MG and DAGP. The onset degradation temperature (Table 3) increased with the increase of PDMS content from HSPU1 to HSPU3. Again, because of the absence of DAGP, the first degradation peak was not prominently visualized in the DTG thermogram of LSPU. However, the second step of thermal degradation of PUs is because of the degradation of urethane, ester, and cycloaliphatic moieties of the chains. The rate of degradation $\left(T_{\mathrm{MAX}}\right)$ was found to be the height in the temperature range of $414-417{ }^{\circ} \mathrm{C}$ which corresponds to the degradation of thermostable moieties, that is, the aromatic unit of TDI. On the other hand, end set degradation $\left(T_{\mathrm{END}}\right)$ corresponds to the degradation of most thermostable moieties such as the Si-O-Si bond of PDMS. From the DTG curves of the synthesized PUs, it is found that with the decrease in the amount of the biobased content from HSPU1 to HSPU3, the degradation temperature also increases. Furthermore, no significant difference in $T_{\mathrm{ON}}, T_{\mathrm{MAX}}$, and $T_{\mathrm{END}}$ set temperature between HSPUs and LSPU was observed. High molecular weight of the LSPU may be the reason for it.

Again, from differential scanning calorimetry (DSC) curves, as displayed in Figure 3c, and the tabulated values (Table 3), glass transition temperature $\left(T_{\mathrm{g}}\right)$ and melting temperature $\left(T_{\mathrm{m}}\right)$ of the soft segment were estimated for the PUs. Several factors affect the $T_{\mathrm{g}}$ value, which include molecular mass of the 
(a)

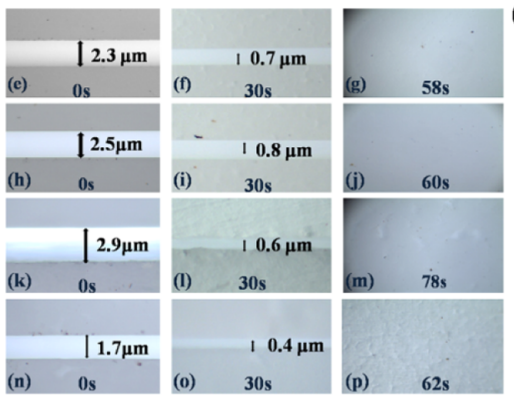

(b)

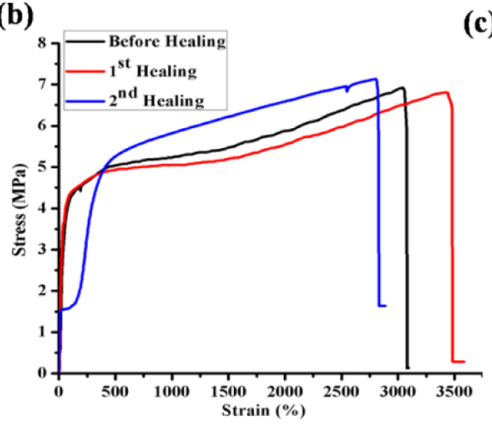

(c)

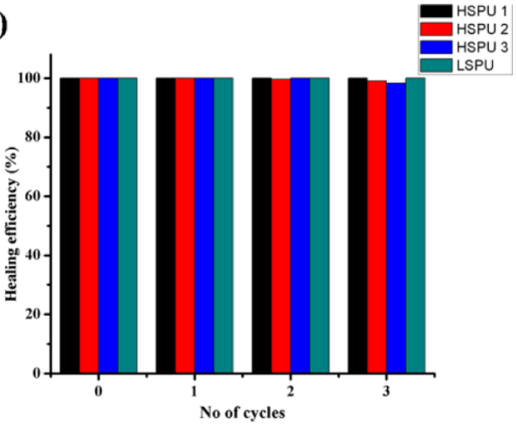

Figure 4. (a) Optical images of mechanically damaged films; HSPU1 [(e,f,g) after exposure of 0,30 , and 58 s of microwave radiation)], HSPU2 $[(\mathrm{h}, \mathrm{i}, \mathrm{j})$ after exposure of 0,30 , and $60 \mathrm{~s}$ of microwave radiation $)]$, HSPU3 [(k,l,m) after exposure of 0,30 , and $78 \mathrm{~s}$ of microwave radiation) $]$, LSPU $[(\mathrm{n}, \mathrm{o}, \mathrm{p})$ after exposure of 0,30 , and $62 \mathrm{~s}$ of microwave radiation) $],(\mathrm{b})$ representative stress-strain curves of HSPU1 before damage and after healing the damage, and (c) healing efficiency (\%) of the PUs for repeated cycles under microwave.

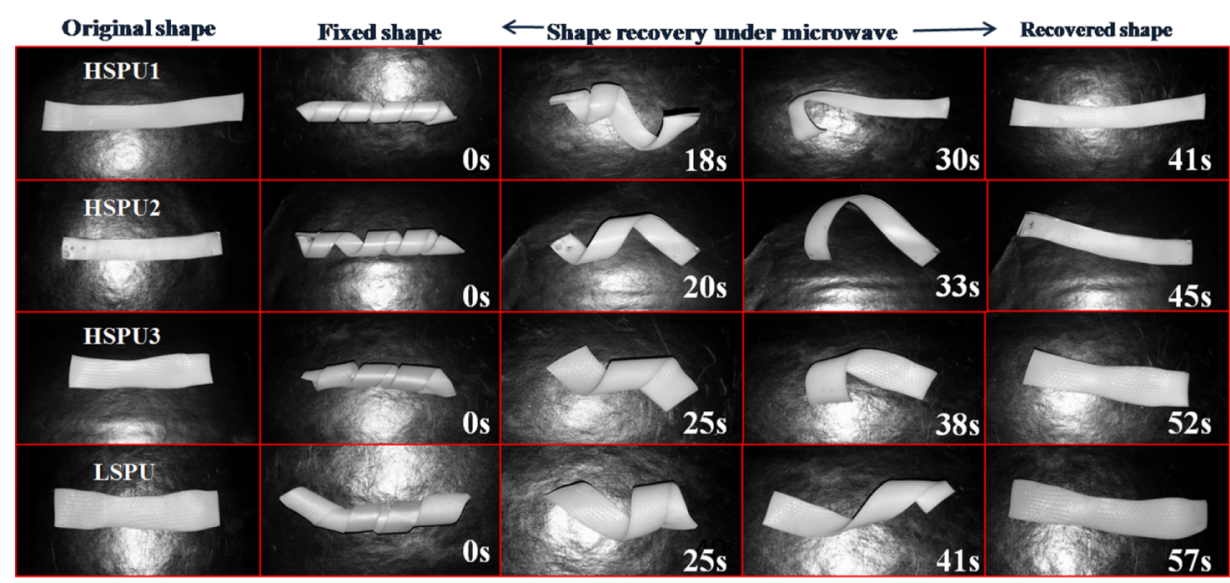

Figure 5. Shape memory behaviors of PUs under microwave $(450 \mathrm{~W})$.

soft and hard segments, chemical structure, cross-linking, crystallization, and the presence of other components. The $T_{\mathrm{g}}$ value of the synthesized HSPUs decreases with the increase of flexible PDMS content as well as the decrease of crystallinity (Table 3). On the contrary, LSPU exhibited the highest $T_{\mathrm{g}}$ value because of the highest crystallinity. The $T_{\mathrm{m}}$ value of the soft segment of PUs varies in the range of $1-2.1^{\circ} \mathrm{C}$. However, all these values are much lower than other PCL-based PUs with similar components reported earlier, which may be because of the plasticization effect of PDMS and MG moieties. ${ }^{17,21}$ This marginal variation of results is the reflection of the similar crystalline nature of the soft segments.

Self-Healing Property. The fractured surfaces' optical images, tensile strength of healed PU strips (up to third cycle), and healing efficiency (Figure $4 a-c$ ) clearly describe the effective self-healing of the PU films. The images of PUs films, before and after healing, support the self-healing behaviors of the synthesized polymers. PUs are segmented polymers with thermodynamically incompatible hard and soft segments. It is well known that the chain mobility of PU enhances at elevated temperature, and hence, interfacial diffusion results in quick healing (Table 3) of the fractured surface. ${ }^{29}$ A further DSC study indicated the low $T_{\mathrm{g}}$ and $T_{\mathrm{m}}$ values for the soft segment of the synthesized PUs exhibited (Table 3). Again, lower the $T_{g}$, faster is the rate of healing. The rate of healing is also related with the shape memory effect. The combination of these two effects is controlling the self-healing rate. ${ }^{6}$ Thus, upon exposure of stimuli such as a microwave $(450 \mathrm{~W})$ and sunlight, the surface polar groups absorbed the required energy and started to oscillate their dipoles which subsequently enhanced the temperature of the exposed surface greater than the $T_{\mathrm{g}}$ and $T_{\mathrm{m}}$ of the soft segments. Hence, a rapid Brownian motion occurred in the soft segment that led to rearrangement of molecular chains in soft segments to repair the crack surface. From the self-healing study, it was observed that with the decrease in the amount of PCL from HSPU1 to HSPU3, the time requirement for the healing process increases. Thus, crystallinity plays an important role in the healing process. HSPU1 contains the highest amount of PCL and hence favors the fastest healing compared to others. Because of very similar extent of crystalline of HSPU2 and LSPU, time required for healing is almost same. All the PU films were effectively healed within 58-70 s under a microwave $(450 \mathrm{~W})$ and $8-10 \mathrm{~min}$ under direct sunlight. Most significantly, this self-healing is accomplished through diffusion and rearrangement processes of the soft segment of PUs and hence the healing process can be repeated number of time. In fact, the tensile strength of PUs remains almost same even after second cycle as shown in Figure $4 \mathrm{~b}$. Thus, the studied PUs showed very fast and efficient self-healing ability with $100 \%$ retention in mechanical property which is much better than other reported self-healing polymers. $^{2,25}$

Shape-Memory Study. The shape fixity (\%), shape recovery (\%), and time required for the shape recovery process of the synthesized PUs are given in Table 3. The shape memory behaviors of the synthesized PUs upon MW irradiation are shown in Figure 5. Shape memory behavior depends on several factors such as the amount of hard to soft 

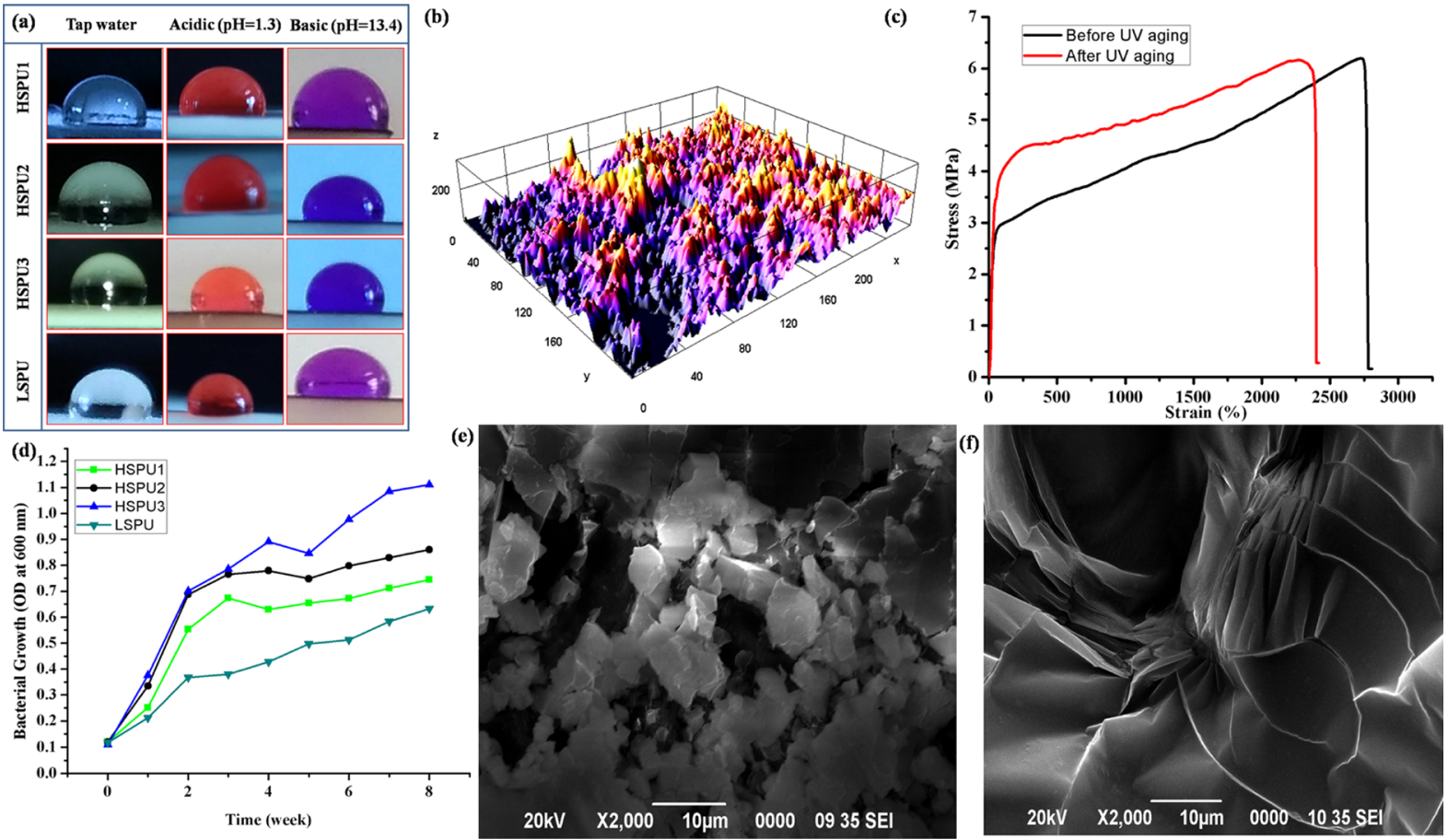

Figure 6. (a) Photos of water droplets at different $\mathrm{pH},(\mathrm{b})$ microroughness of the HSPU3 surface captured by a digital microscope, and the image is processed by ImageJ software, (c) stress-strain profiles before and after UV aging, (d) growth curve of P. aeruginosa on PUs, and (e,f) biodegraded surface of HSPU3 and LSPU.

segment ratio, structure of components used as the hard segment (IPDI, TDI, and MG), molecular weight of the soft segment, molecular weight of PU, and so forth. ${ }^{26}$ When the PU strips were heated above their melting temperature of the soft segments, Brownian motion occurred among the molecular chains. Thus, they can be easily deformed by applying an external force. Rapid freezing of the stretched PU strips below the melting temperature at $-(15 \pm 5){ }^{\circ} \mathrm{C}$ restricted the chain mobility of the polymer as well as decreased the entropy of the system. Thus, upon removal of the external force, the molecular chains were unable to gain required energy to reverse back the deformation, and at the same time, covalent cross-linking in the hard segment and the rigid crystalline segment prevented the sliding of the polymer domains. Because of the same reason, shape fixity decreases with the decrease of the crystalline nature from HSPU1 to HSPU3. LSPU and HSPU1 displayed almost a similar type of crystallinity, thus resulting in better fixity compared to HSPU2 and HSPU3. Upon reheating the PU strips above their melting temperature, chain mobility increases, resulting in the increase in the entropy of the system which helps to regain its original stable coiled architecture. The increase speed of shape recovery $(57-41 \mathrm{~s})$ under the exposure of MW from LSPU3 to HSPU1 is due to the increase of elastic strain energy. Again, this elastic strain energy increases with the increase of urethane linkages, physical cross-linking, and molecular weight of such PUs. ${ }^{30}$

Surface Hydrophobicity Study. The hydrophobic nature of the PU surface depends upon both the surface chemical composition (intrinsic hydrophobicity) and the surface geometrical microstructures (roughness). ${ }^{12,13}$ The structure of the synthesized PU contains nonpolar moieties such as long aliphatic hydrocarbon chains of MG and DAGP and aromatic and aliphatic parts of diisocyanates which provided the intrinsic hydrophobic character in the structure. In addition to the above, the nonpolar nature and low surface energy of PDMS also significantly contribute in enhancing such hydrophobicity as reflected in the digital images of water droplets of PU surfaces (Figure 6a). Furthermore, the amorphous PDMS moiety is not compatible with the crystalline PCL moiety of the PU structure. ${ }^{21}$ This incompatibility created microroughness (Figure $6 \mathrm{~b}$ ) on the surface of PU films. The combination of these two effects provides a hydrophobic surface. The contact angle increases with the increase of the PDMS content as well as increase in incompatibility from HSPU1 to HSPU3, as given in Table 3. Most interestingly, the difference between the advancing angle and the receding angle, that is, the angle of hysteresis, is an important factor for rolling the water droplets on the surface of PUs. The lower the value of angle of hysteresis, the higher is the hydrophobicity and better is the self-cleaning effect. Furthermore, both in acidic and alkaline $\mathrm{pH}$, the results of the contact angle were almost the same, indicating their applicability under all atmospheric conditions.

UV-Aging Study. Synthesized PUs displayed excellent UV resistance as supported by retention of the mechanical properties after UV aging (Table 3). UV-aged PU strips showed slight reduction in flexibility as measured by elongation at break (Figure 6c), although the tensile strength value remains almost constant. Basically, during UV aging both chain scission and cross-linking took place. ${ }^{29}$ These two contradictory effects on mechanical strength cancel each other, so the resulting strength remains almost the same, while the reduction of flexibility upon UV exposure may be due to additional crosslinking as well as chain scission from oxidation reaction. Even though the exact mechanism of the photolytic degradation of $\mathrm{PU}$ is not known but literature advocated photo-oxidation of $-\mathrm{CH}_{2}$ groups result slightly yellowish coloration of the PU 
strips. ${ }^{31,32}$ The better UV resistance of HSPUs than LSPUs is due to the hyperbranched structure with confined geometry of the former. However, as the amount of UV-active components in all HSPUs is the same, the effect was not significantly different.

\section{CONCLUSIONS}

From this study, it can be concluded that the siliconecontaining high-molecular weight thermoplastic PU elastomer with hyperbranched architecture was successfully synthesized by the conventional prepolymerization technique for the first time. Instrumental analyses, especially NMR spectral studies, help to understand the structure of the synthesized PU elastomer. The structural architecture and appropriate composition of the right components of PU can lead to exceptional flexibility, high toughness, high thermal, UV, and chemical resistance, as well as special attributes such as excellent intrinsic repeatable multistimuli-responsive selfhealing, shape memory, and self-cleaning ability. Additionally, biodegradability of the synthesized renewable resource-based PUs might solve genuine problems of land and water pollution and solid waste management issues. Thus, the studied biodegradable smart PU can hold significant promise as a sustainable material for its potential applications.

\section{EXPERIMENTAL SECTION}

Materials. Bis(hydroxyalkyl)-PDMS $\left(M_{\mathrm{n}} \approx 5600 \mathrm{~g} \cdot \mathrm{mol}^{-1}\right.$, Sigma-Aldrich, Japan), dimer acid (DA, $M_{\mathrm{n}} \approx 570 \mathrm{~g} \mathrm{~mol}^{-1}$, Sigma-Aldrich, USA), glycerol (Merck, India), PCL $\left(M_{\mathrm{n}}=\right.$ $2000 \mathrm{~g} \mathrm{~mol}^{-1}$, Sigma-Aldrich, USA), sunflower oil (SigmaAldrich, USA), and 1,4-butanediol (BD, Merck, India) were dried at elevated temperature under vacuum for at least $12 \mathrm{~h}$ before use. IPDI (Sigma-Aldrich, USA), TDI (Merck, Germany), oxalic acid (Rankem, India), potassium hydroxide (Rankem, India), maleic anhydride (Merck-Schuchardt), butylamine (Sigma-Aldrich, USA), bromophenol blue indicator $\mathrm{pH}$ 3.5-4.6 (Merck, India), isopropyl alcohol (SRL, Mumbai, India), para-toluene sulfonic acid ( $p$-TSA SRL, Mumbai, India), hydrochloric acid (36\%) (Rankem, India), $\mathrm{CaO}$ (Merck, India), and toluene (Merck, India) were used as received from the supplier. N,N-Dimethyl acetamide (Merck, India) was used after drying overnight using calcium oxide, followed by distillation under reduced pressure. Xylene (Merck, India) was used only after normal distillation.

Preparation of DAGP. DAGP was prepared by esterification reaction of $3 \mathrm{~mol}$ of DA with $6 \mathrm{~mol}$ of glycerol in the presence of $p$-TSA $\left(0.5\right.$ wt $\%$ of DA) at $160{ }^{\circ} \mathrm{C}$ for $2 \mathrm{~h}$, as reported earlier. ${ }^{17}$

Preparation of MG. MG of sunflower oil was prepared by the standard glycerolysis process, where two equivalents of glycerol react with one equivalent of sunflower oil in the presence of $\mathrm{CaO}(0.05 \mathrm{wt} \%$ of sunflower oil $)$ at $(220 \pm 5){ }^{\circ} \mathrm{C}$ under $\mathrm{N}_{2}$ atmosphere. ${ }^{30}$

Synthesis of HSPU. HSPU was synthesized by a two-step prepolymerization technique using a three-neck round-bottom flask equipped with a nitrogen gas inlet, a mechanical stirrer, a Teflon septum, and a thermometer. PCL (2.1 mM, $4.2 \mathrm{~g})$, PDMS (0.1 mM, $0.56 \mathrm{~g})$, and DAGP $(0.2 \mathrm{mM}, 0.15 \mathrm{~g})$ were placed in the reaction vessel with $1.5 \mathrm{~mL}$ xylene under constant stirring, and the solid content was maintained at about $80 \mathrm{wt}$ $\%$. After dissolving PCL, TDI $(3.2 \mathrm{mM}, 0.557 \mathrm{~g})$ was added dropwise to the abovementioned reaction mixture by using a syringe at room temperature under nitrogen atmosphere. Then, the reaction mixture was heated at $85-90{ }^{\circ} \mathrm{C}$ for $4 \mathrm{~h}$ until the desired viscosity was obtained which was considered as the prepolymer. After cooling the reaction mixture, the calculated amount of MG (4.6 mM, $1.628 \mathrm{~g})$ and IPDI ( $4 \mathrm{mM}$, $0.88912 \mathrm{~g}$ ) was added with $8 \mathrm{~mL}$ of xylene to maintain the solid content at $50 \mathrm{wt} \%$. The temperature of the reaction mixture was then increased step by step up to $110{ }^{\circ} \mathrm{C}$. Under this condition, the reaction was continued for $5 \mathrm{~h}$ until very high viscosity was achieved without any gel formation. The absence of an isocyanate band at $2270 \mathrm{~cm}^{-1}$ in the FT-IR spectrum and butyl amine test supported the completion of the reaction. By following the exact same procedure, other HSPUs were synthesized with the same amount of the branching component but different amounts of PCL and PDMS. The actual compositions of all HSPUs with their respective code are given in Table 1 . The linear silicone-containing PU (LSPU) with the same composition was also prepared by replacing branch generating unit DAGP with an equivalent amount of BD. A small part of the synthesized HSPU solution was precipitated in water repeatedly for NMR analyses. The remaining amount was cast on a glass plate $(10 \mathrm{~mm} \times 60 \mathrm{~mm}$ $\times 5.9 \mathrm{~mm})$, a galvanized tin sheet $(150 \mathrm{~mm} \times 50 \mathrm{~mm} \times 0.61$ $\mathrm{mm}$ ), and kept for $48 \mathrm{~h}$ in room temperature to remove the solvent, and then these PU films were dried in a convection oven at $70{ }^{\circ} \mathrm{C}$ to remove the remaining amount of the solvent along with any entrapped volatile to obtain a film with thickness of 1-2 mm for other tests and analyses.

Characterization. Structural Analysis. Structural characterization of the synthesized PUs was done with the help of different spectroscopic and diffraction techniques such as FT$\mathrm{IR}$, NMR, and XRD, as reported elsewhere, and a brief description is provided in the Supporting Information. ${ }^{17}$

Physical, mechanical, and thermal properties and self-healing ability of the PUs were also evaluated, and details of the processes are given in the Supporting Information.

Shape Memory Test. To evaluate the shape memory behavior of the PU strips, the spiral bending test was performed. At first, they were heated at $60{ }^{\circ} \mathrm{C}$ for $5 \mathrm{~min}$ and folded in the form of the spiral shape. Immediately, the spiralshaped samples were frozen to release the stress in an ice bath for $10 \mathrm{~min}$. For shape recovery of the PU strips, they were projected under different stimuli such as MW (at $450 \mathrm{~W}$ ), heat $\left(60{ }^{\circ} \mathrm{C}\right)$, and sunlight $(35 \pm 2){ }^{\circ} \mathrm{C}$. The same procedure was repeated up to 5 times, and the average result was given for each compositions. The shape recovery and shape fixity as two shape-memory parameters are calculated from the following equations

$$
\begin{aligned}
& \text { Shape fixity }(\%)=\left\{\left(90-\theta_{\mathrm{f}}\right) / 90\right\} \times 100 \\
& \text { Shape recovery }(\%)=\left\{\left(180-\theta_{\mathrm{r}}\right) / 180\right\} \times 100
\end{aligned}
$$

where $\theta_{\mathrm{f}}$ represents the released angle after cooling and $\theta_{\mathrm{r}}$ represents the angle after recovery. ${ }^{26}$ The values of $\theta_{\mathrm{f}}$ and $\theta_{\mathrm{r}}$ are calculated as displayed in Figure $\mathrm{S} 1$ of the Supporting Information.

Self-Cleaning Test. The self-cleaning property of the synthesized PU strips was investigated by visualizing the digital photographs of acidic, basic, and neutral water droplets on the polymer surface and measuring their advancing angle, receding angle, and the angle of hysteresis by using ImageJ software. 
UV-Aging and Chemical Resistance Test. The UV aging test as reported earlier and the chemical resistance test as per ASTM D 543-67 method are briefly discussed in the Supporting Information.

Biodegradation Test. The McFarland turbidity method was used for the biodegradation study of the synthesized PUs, as reported briefly in the Supporting Information. ${ }^{33}$

\section{ASSOCIATED CONTENT}

\section{S Supporting Information}

The Supporting Information is available free of charge on the ACS Publications website at DOI: 10.1021/acsomega.8b00734.

Structural analysis, determination of physical properties, mechanical properties, thermal properties, self-healing ability, UV aging, chemical resistance, and biodegradation test for the synthesized PUs; results and discussion for the chemical resistance study and the biodegradation study; table of weight loss (\%) of PU films in different chemical media; the angle measured during shape memory; and surface 3D plot of the PUs (PDF)

\section{AUTHOR INFORMATION}

\section{Corresponding Author}

*Email: karakniranjan@gmail.com. Phone: +91-3712-267009. Fax: +91-3712-267006.

\section{ORCID}

Niranjan Karak: 0000-0002-3402-9536

\section{Author Contributions}

The manuscript was written through contributions of all authors. All authors have given approval to the final version of the manuscript. Contributing author: T.G. Email: tuhinchem1992@gmail.com.0000-0003-1869-4912.

\section{Notes}

The authors declare no competing financial interest.

\section{ACKNOWLEDGMENTS}

The authors express their gratitude to DST, India through the grant no. EMR/2016/001598, dated 04-Jan-2017.

\section{REFERENCES}

(1) Karak, N. Biobased Smart Polyurethane Nanocomposites: From Synthesis to Applications; Royal Society of Chemistry: Cambridge, U.K., 2017.

(2) Zhao, J.; Xu, R.; Luo, G.; Wu, J.; Xia, H. Self-healing poly(siloxane-urethane) elastomers with remoldability, shape memory and biocompatibility. Polym. Chem. 2016, 7, 7278-7286.

(3) Heo, Y.; Sodano, H. A. Self-healing polyurethanes with shape recovery. Adv. Funct. Mater. 2014, 24, 5261-5268.

(4) Parkin, I. P.; Palgrave, R. G. Self-cleaning coatings. J. Mater. Chem. 2005, 15, 1689-1695.

(5) Keller, M. W.; White, S. R.; Sottos, N. R. A Self-Healing Poly(Dimethyl Siloxane) Elastomer. Adv. Funct. Mater. 2007, 17, 2399-2404.

(6) Yang, Y.; Urban, M. W. Self-healing polymeric materials. Chem. Soc. Rev. 2013, 42, 7446-7467.

(7) Thakur, V. K.; Kessler, M. R. Self-healing polymer nanocomposite materials: A review. Polymer 2015, 69, 369-383.

(8) Ghosh, B.; Urban, M. W. Self-repairing oxetane-substituted chitosan polyurethane networks. Science 2009, 323, 1458-1460.

(9) Roy, N.; Bruchmann, B.; Lehn, J.-M. Dynamers: dynamic polymers as self-healing materials. Chem. Soc. Rev. 2015, 44, 37863807.
(10) Bode, S.; Zedler, L.; Schacher, F. H.; Dietzek, B.; Schmitt, M.; Popp, J.; Hager, M. D.; Schubert, U. S. Self-healing polymer coatings based on crosslinked metallosupramolecular copolymers. Adv. Mater. 2013, 25, 1634-1638.

(11) Zheng, Q.; Ma, Z.; Gong, S. Multi-stimuli-responsive selfhealing metallo-supramolecular polymer nanocomposites. J. Mater. Chem. A 2016, 4, 3324-3334.

(12) Ragesh, P.; Anand Ganesh, V.; Nair, S. V.; Nair, A. S. A review on 'self-cleaning and multifunctional materials'. J. Mater. Chem. A 2014, 2, 14773-14797.

(13) Li, X.-M.; Reinhoudt, D.; Crego-Calama, M. What do we need for a superhydrophobic surface? A review on the recent progress in the preparation of superhydrophobic surfaces. Chem. Soc. Rev. 2007, 36, 1350-1368.

(14) Ramakrishna, S.; Kumar, K. S. S.; Mathew, D.; Nair, C. P. R. A robust, melting class bulk superhydrophobic material with heathealing and self-cleaning properties. Sci. Rep. 2015, 5, 18510.

(15) Bayer, I. S.; Steele, A.; Martorana, P. J.; Loth, E. Fabrication of superhydrophobic polyurethane/organoclay nano-structured composites from cyclomethicone-in-water emulsions. Appl. Surf. Sci. 2010, $257,823-826$.

(16) Lomölder, R.; Plogmann, F.; Speier, P. Selectivity of isophorone diisocyanate in the urethane reaction influence of temperature, catalysis, and reaction partners. J. Coat. Technol. 1997, 69, 51-57.

(17) Ghosh, T.; Karak, N. Biobased multifunctional macroglycol containing smart thermoplastic hyperbranched polyurethane elastomer with intrinsic self-healing attribute. ACS Sustainable Chem. Eng. 2018, 6, 4370-4381.

(18) Wu, N.; Huang, L.; Zheng, A. Synthesis and properties of polystyrene/polydimethylsiloxane graft copolymers. Front. Chem. China 2006, 3, 350-356.

(19) Das, B.; Konwar, U.; Mandal, M.; Karak, N. Sunflower oil based biodegradable hyperbranched polyurethane as a thin film material. Ind. Crops Prod. 2013, 44, 396-404.

(20) Zhang, T.; Howell, B. A.; Dumitrascu, A.; Martin, S. J.; Smith, P. B. Synthesis and characterization of glycerol-adipic acid hyperbranched polyesters. Polymer 2014, 55, 5065-5072.

(21) Pergal, M. V.; Antić, V. V.; Govedarica, M. N.; Goäevac, D.; Ostojić, S.; Djonlagić, J. Synthesis and characterization of novel urethane-siloxane copolymers with a high content of PCL-PDMSPCL segments. J. Appl. Polym. Sci. 2011, 122, 2715-2730.

(22) Thakur, S.; Karak, N. Castor oil-based hyperbranched polyurethanes as advanced surface coating materials. Prog. Org. Coat. 2013, 76, 157-164.

(23) Petrović, S. Z.; Hong, D.; Javni, I.; Erina, N.; Zhang, F.; Ilavský, $\mathrm{J}$. Phase structure in segmented polyurethanes having fatty acid-based soft segments. Polymer 2013, 54, 372-380.

(24) Weinhold, F.; West, R. The nature of the silicon-oxygen bond. Organometallics 2011, 30, 5815-5824.

(25) Fu, G.; Yuan, L.; Liang, G.; Gu, A. Heat-resistant polyurethane films with great electrostatic dissipation capacity and very high thermally reversible self-healing efficiency based on multi-furan and liquid multi-maleimide polymers. J. Mater. Chem. A 2016, 4, 42324241.

(26) Rehman, H. U.; Chen, Y.; Hedenqvist, M. S.; Li, H.; Xue, W.; Guo, Y.; Guo, Y.; Duan, H.; Liu, H. Self-healing shape memory PUPCL copolymer with high cycle life. Adv. Funct. Mater. 2017, 28, 1704109.

(27) Trovati, G.; Sanches, E. A.; Neto, S. C.; Mascarenhas, Y. P.; Chierice, G. O. Characterization of polyurethane resins by FTIR, TGA, and XRD. J. Appl. Polym. Sci. 2010, 115, 263-268.

(28) Hazmi, A. S. A.; Pauzi, N. N. P. N.; Maurad, Z. A.; Abdullah, L. C.; Aung, M. M.; Ahmad, A.; Salleh, M. Z.; Tajau, R.; Mahmood, M. H.; Saniman, S. E. Understanding intrinsic plasticizer in vegetable oilbased polyurethane elastomer as enhanced biomaterial. J. Therm. Anal. Calorim. 2017, 130, 919-933.

(29) Shahabadi, S. I. S.; Kong, J.; Lu, X. Aqueous-Only, Green Route to Self-Healable, UV-Resistant, and Electrically Conductive Polyur- 
ethane/Graphene/Lignin Nanocomposite Coatings. ACS Sustainable Chem. Eng. 2017, 5, 3148-3157.

(30) Kalita, H.; Karak, N. Bio-based hyperbranched shape memory polyurethanes: effect of different vegetable oils. J. Appl. Polym. Sci. 2014, 131, 39579.

(31) Das, S.; Pandey, P.; Mohanty, S.; Nayak, S. K. Study of UV aging on the performance characteristics of vegetable oil and palm oil derived isocyanate based polyurethane. Korean J. Chem. Eng. 2017, 34, 523-538.

(32) Boubakri, A.; Guermazi, N.; Elleuch, K.; Ayedi, H. F. Study of UV-aging of thermoplastic polyurethane material. Mater. Sci. Eng. A 2010, 527, 1649-1654.

(33) Gogoi, S.; Karak, N. Biobased biodegradable waterborne hyperbranched polyurethane as an ecofriendly sustainable material. ACS Sustainable Chem. Eng. 2014, 2, 2730-2738. 